\title{
Synovial response of Papio cynocephalus to exogenous antigen: histological and immunoperoxidase observations
}

\author{
I. S. ALEXANDER, ${ }^{1}$ D. L. GARDNER, ${ }^{1}$ AND P. N. SKELTON-STROUD ${ }^{2}$ \\ From the ${ }^{1}$ Department of Histopathology, University of Manchester, and ${ }^{2}$ Ciba-Geigy Ltd, Wilmslow
}

SUMMARY Acute experimental synovitis was produced by intra-articular challenge of 3 baboons (Papio cynocephalus) sensitised with ovalbumin. Haemagglutination tests revealed high titres of circulating antiovalbumin antibody. Measurements were made of articular diameter, circumference, and temperature before the animals were killed on days 1,5 , and 20 . The sterile synovitis was investigated microscopically and by immunoperoxidase methods. $\operatorname{IgG}, \operatorname{IgM}, \operatorname{IgA}, \mathrm{C} 3$, and fibrin were identified within the synovial membranes which were extensively infiltrated with plasmacytes and other mononuclear cells. It was concluded that the baboon can respond to exogenous antigen histologically in a manner analogous to that of nonprimates. Some features of the response recall those of the synovitis of active human rheumatoid disease.

In the search for the cause of rheumatoid arthritis (RA), attempts to transmit the disease to species other than man have continued. Synovial fluid cells or synovial membrane cells have been inoculated. The baboon Papio cynocephalus revealed no evidence of arthritis after such inoculations during a 3-year period of observations. ${ }^{1}$ One contributory factor accounting for the absence of a response may have been the low reactivity of baboon synovia to antigenic challenge. This possibility has been examined by Hunneyball et al. ${ }^{2}$ in experiments in which the histological responses of the baboon synovial membranes were, however, not the primary interest.

It appeared desirable to take advantage of the availability of 3 further baboons to analyse the synovial responses to antigenic challenge in more detail and to apply to the synovial membranes immunoperoxidase tests that could aid the immunological definition of any synovial response that occurred.

\section{Materials and methods}

Three baboons (Papio cynocephalus) were each immunised by 2 intramuscular injections of $10 \mathrm{mg}$ ovalbumin in Freund's complete adjuvant, given 14 days apart. ${ }^{2}$ Ten days after the second injection

Accepted for publication 30 April 1982.

Correspondence to Professor D. L. Gardner, Department of Pathology, Stopford Building, Oxford Road, Manchester M13 9PT. the right knee was injected with $5 \mathrm{mg}$ ovalbumin in $0.5 \mathrm{ml}$ sterile saline, the left knee with saline alone. Blood was taken at the time of each immunisation and post mortem. Sera were separated for haemagglutination tests to demonstrate antiovalbumin antibody. Measurements of articular diameter were made by calipers before and at intervals after the injections. Articular circumferences were determined with string placed round the joint and read against a linear scale. Joint temperatures were recorded by skin thermometer.

Animals were killed by pentobarbitone overdose 1,5 , and 20 days after intra-articular challenge. Both knee joints were opened and photographed; synovial membrane was taken for bacteriological culture. Synovial membranes from the knees and elbow, menisci, femoral condyles, and tibia were fixed in neutral buffered formalin. Paraffin sections cut at $5 \mu \mathrm{m}$ were stained with haematoxylin and eosin.

Additional synovial sections were floated briefly on a $43^{\circ} \mathrm{C}$ water bath and mounted on glass slides coated with chrome alum gelatin. Sections were deparaffinised, rehydrated with methanol, and washed with distilled water. After treatment with trypsin ${ }^{3}$ sections were placed in hydrogen peroxide in methanol to inhibit endogenous peroxidase activity. An unlabelled antibody, peroxidase-antiperoxidase (PAP) method was employed ${ }^{4}$ with antihuman antisera raised in rabbits to IgG ( $\gamma$-chains), IgM ( $\mu$-chains), $\operatorname{IgA}(\alpha$-chains and secretory piece), C3 complement ( $\beta$-1-A, $\beta-1-C$ globulin), and fibrinogen 
(Dako). Primary antisera were used at dilutions of $1 / 5000$ for $\operatorname{IgG}, \operatorname{Ig} \mathrm{A}$, and fibrin and $1 / 2000$ for $\operatorname{IgM}$ and $\mathrm{C} 3$. The concentrations of the antiglobulin bridge (swine antirabbit Igs, Dako) and rabbit PAP (Dako) were $1 / 50$ and $1 / 100$ respectively. Peroxidase was demonstrated with a freshly prepared solution of 3-amino-9-ethylcarbazole. As controls the primary antisera were replaced with similarly diluted normal rabbit serum and homologous antigen-absorbed immune rabbit serum. Sections were mounted in glycerin jelly.

\section{Results}

Two weeks after sensitisation, haemagglutination tests revealed high titres of circulating antiovalbumin antibody (Table 1).

Clinical evidence of arthritis was recognised within 3 hours of challenge. Joint temperature became maximal 24 hours after IA injection; circumference and

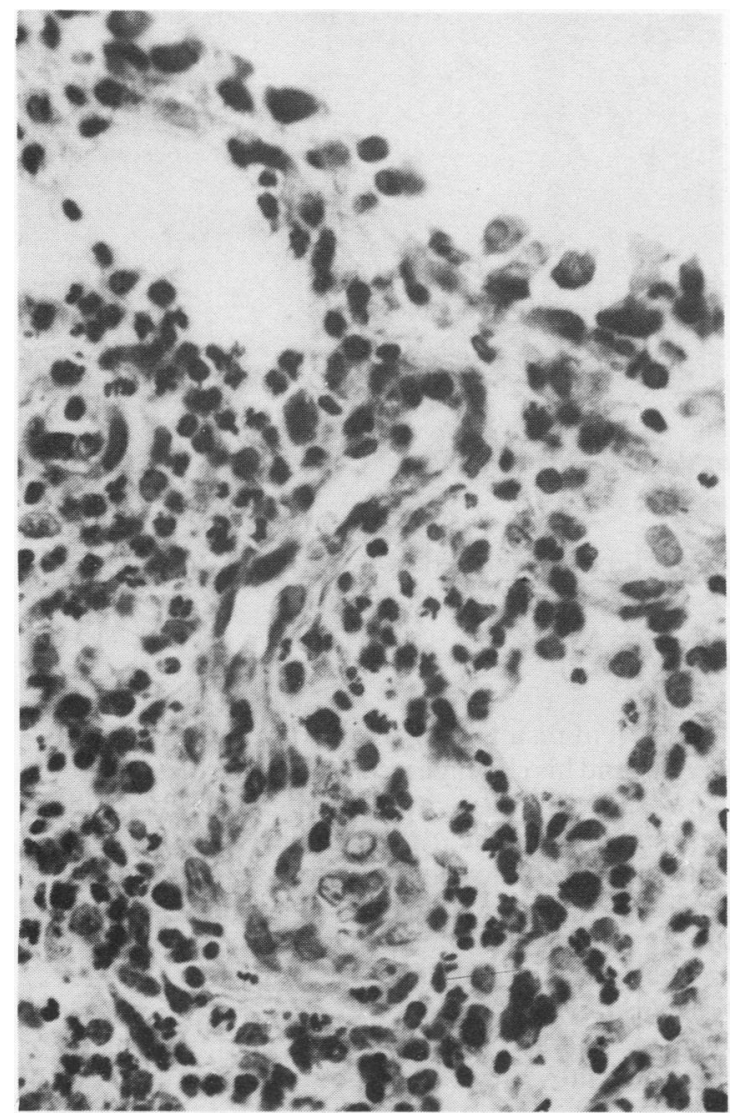

Fig. 1 Pronounced polymorph infiltrate within the synovium 5 days after intra-articular challenge.

(Haematoxylin and eosin $(H E), \times 500)$. diameter were greatest between days 2 and 5 after challenge; all measurements were still raised at day 20. Experimental joints opened post mortem were haemorrhagic; an inflammatory exudate was present, a characteristic most prominent 5 days after challenge. Control, saline-injected joints appeared normal.

Synovial membranes taken for culture showed no evidence of bacterial infection. Control joint histology was normal apart from slight hyperaemia 1 day

Table 1 Reciprocal agglutination titres for antiovalbumin antibody

\begin{tabular}{llll}
\hline Baboon & $\begin{array}{l}\text { At immuni- } \\
\text { sation }\end{array}$ & $\begin{array}{l}\text { At reimmuni- } \\
\text { sation }\end{array}$ & $\begin{array}{l}\text { At post- } \\
\text { mortem }\end{array}$ \\
\hline 1 & 0 & 1280 & 1280 \\
2 & 0 & 2560 & 2560 \\
3 & 0 & 2560 & 5120 \\
\hline
\end{tabular}

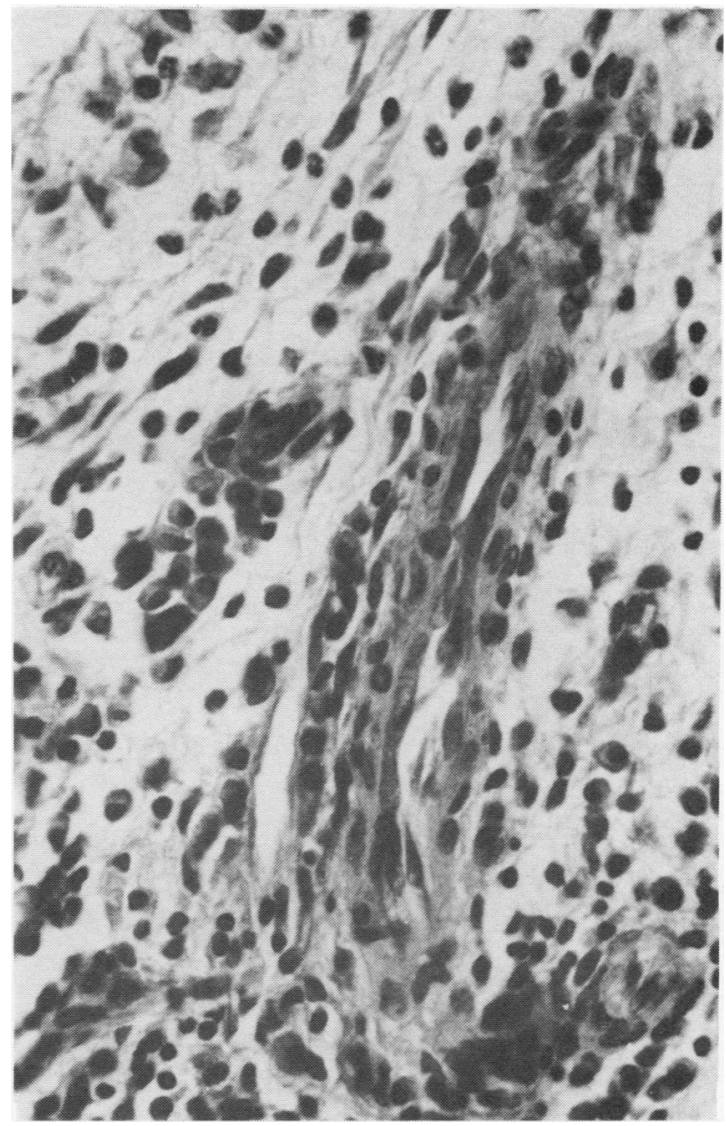

Fig. 2 Increased number of plasma cells within the synovium by day 20. (HE, $\times 500)$. 
after challenge. The synovium of the day 1 experimental knee was severely hyperaemic and infiltrated with polymorphs. At day 5 there was an increasing lymphocytic and plasmacytic infiltrate, subsynovial haemorrhage, margination of intravascular polymorphs, and perivascular cell accumulations. By day 20 there was synovial cell hyperplasia, the formation of villi, and increased numbers of plasma cells. Representative fields are illustrated in Figs 1 and 2.

At day 1 small amounts of fibrin were detected in some synovial blood vessels walls, in subsynovial connective tissue and in the synovial intima. Neither IgG, IgM, IgA, nor C 3 were identified. Five days after intra-articular injection $\mathrm{IgG}$ had accumulated at vascular endothelial surfaces and within the vascular intima (Fig. 3). IgM and C3 were recognised together with a weak response for $\operatorname{IgA} .^{5}$ A positive reaction for IgG, IgM, IgA, and C 3 was seen within the intercellular tissue spaces. By day 20 numerous plasma cells reacted strongly for IgG (Fig. 4) but very weakly for

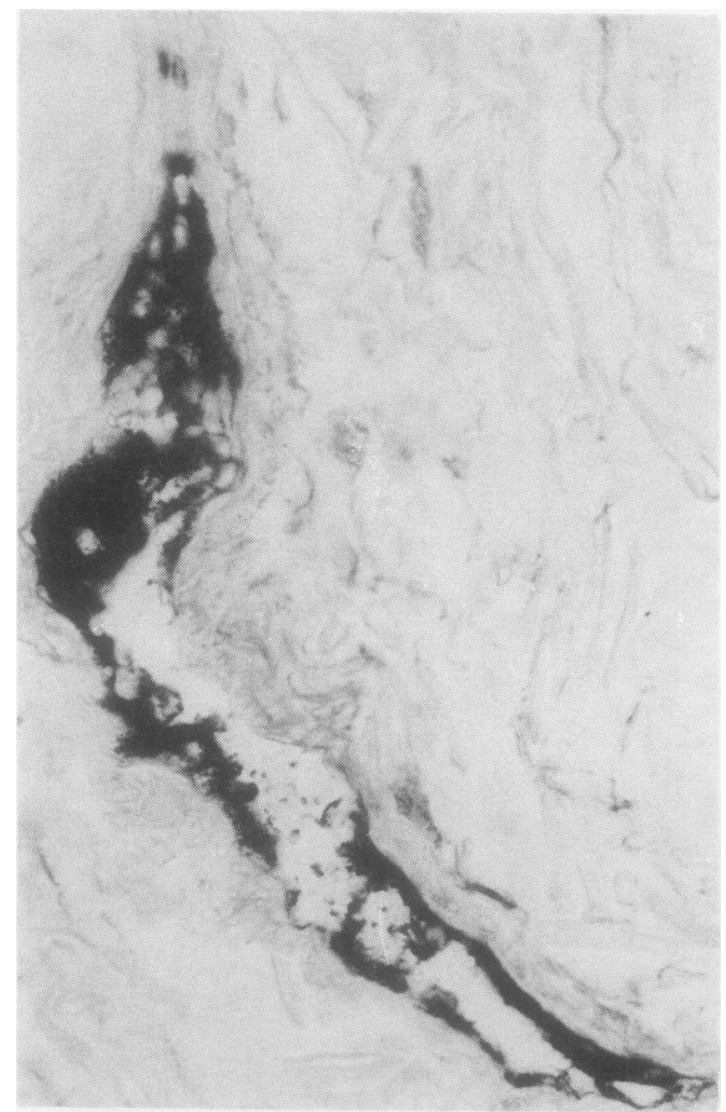

Fig. 3 Accumulation of IgG within a synovial blood vessel wall 5 days after intra-articular challenge. (PAP, $\times 500)$.

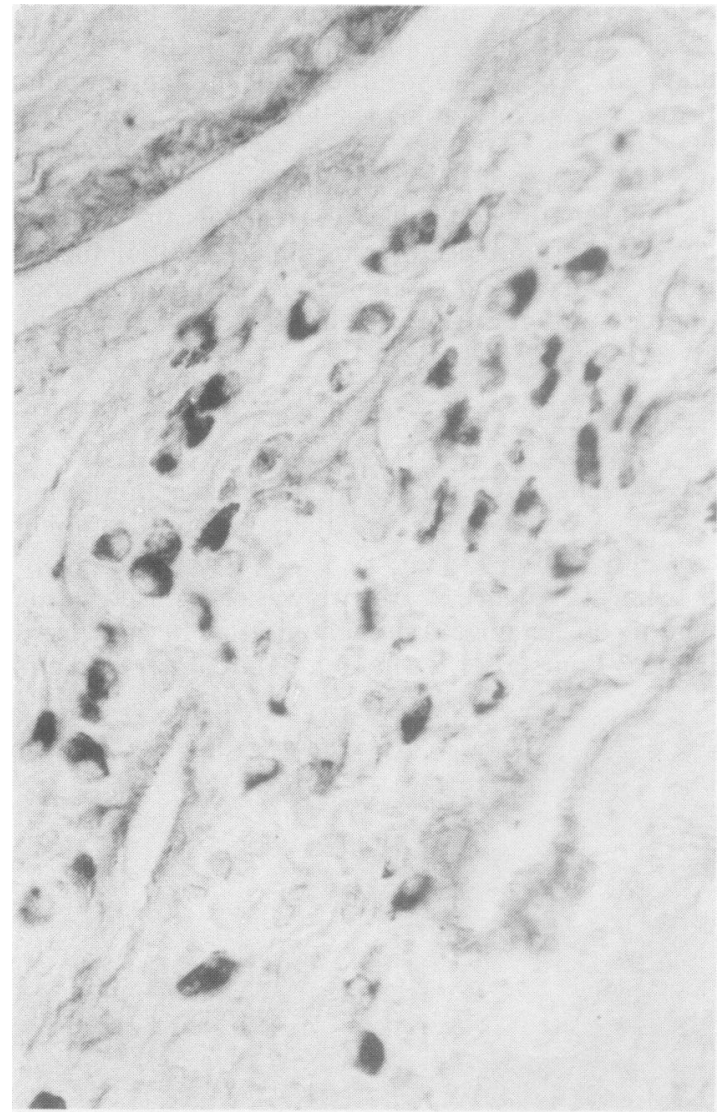

Fig. 4 IgG-positive cells detected within the synovium by day 20. (PAP, $\times 500)$.

IgM. Immunoperoxidase controls confirmed the specificity of reaction in all cases.

\section{Discussion}

The present results confirm the observations of Hunneyball and his colleagues ${ }^{2}$ that the sensitised baboon can respond to intra-articular challenge by exogenous antigen by the development of acute sterile arthritis. The reaction is analogous to that of the sensitised rabbit ${ }^{5}$ and chicken ${ }^{6}$ but differs from that of the guinea-pig, in which plasmacytes are few and inconspicuous. ${ }^{6}$ This paper extends these observations by analysing the nature of the cellular reactions 1,5 , and 20 days after challenge; and demonstrates that the synovial blood vessels, the interstitial connective tissue, and the plasmacytes of the inflamed synovial membrane variously contain or are bound to immunoglobulins $\mathrm{G}, \mathbf{M}$, and $\mathrm{A}$, fibrin, and $\mathrm{C} 3$, the coincidence of which at sites of inflammation denotes 
immune complex formation as a basis for the inflammation.

It is believed that, in the wild, baboons can be exposed to viruses of kinds that have been proposed as causes of human RA. Nevertheless there is evidence to show that both in the wild or in prolonged captivity, where contact with a RA virus could be assumed to be frequent, baboons and rhesus monkeys rarely develop rheumatoid-like polyarthritis. $^{7}$ This slender evidence is all the more surprising because it is clear that dogs $s^{\times}$may manifest a RA-like polyarthritis. One explanation for the nonreactivity of baboons may be premature death. Particularly in their natural environment, baboons are likely to survive for limited life spans: trauma and other environmental causes can be held responsible for relatively early death, which may take place before the end of the incubation period of a candidate slow virus. This view has much in common with the epidemiological and social evidence that, in man, RA is a modern plague in an aging population, first revealed when the great epidemics of infectious disease began to be controlled by public health measures.

Whether, therefore, primates do not develop RA-like polyarthritis because virus does not gain access to synovial target tissues, or whether the animals normally die before the incubation period of a causal slow virus is concluded, it appears reasonably certain that there is no inherent humoral characteristic of the baboon immune system or synovium that precludes the development of RA-like disease under appropriate circumstances of challenge by foreign microbial antigen. The possibility of an alternative explanation related to cell-mediated reactivity remains to be assessed in further experiments.

The support of the Arthritis and Rheumatism Council for Research and of the Medical Research Council is gratefuly acknowledged.

\section{References}

1 MacKay J M K, Sim A K, McCormick J N, et al. Aetiology of rheumatoid arthritis: an attempt to transmit an infective agent from patients with rheumatoid arthritis to baboons. Ann Rheum Dis 1983 ; 42: 443-7.

2 Hunneyball I M, Harrison G V L, Stanworth D R. The production of experimental arthritis in baboons. IRCS J Med Sci 1979; 7: 517.

3 MacIver A G, Giddings J, Mepham B L. Demonstration of extracellular immunoproteins in formalin-fixed renal biopsy specimens. Kidney Int 1979; 16: 632-6.

4 Sternberger L A. Immunocytochemistry. 2nd ed. New York: Wiley, 1979.

5 Hasselbacher P, Nacht J L, Labosky D A. Antigen-induced arthritis: an immunohistologic study of articular tissue and synovial fluid using the horseradish peroxidase technique. $J$ Rheumatol 1980; 7: 596-608.

6 Dumonde D C. Kelly R H, Morley J. Lymphoid and microvascular dysfunction in experimental models of rheumatoid inflammation. In: Dumonde D C, ed. Infection and Immunology in the Rheumatic Diseases. Oxford: Blackwell, 1976: 375-403.

7 Bywaters E G L. Observations on chronic polyarthritis in monkeys. J $R$ Soc Med 1981; 74: 794-9.

8 Schumacher H R, Newton C, Halliwell R E W. Synovial pathologic changes in spontaneous canine rheumatoid-like arthritis. Arthritis Rheum 1980; 23: 412-23. 